\title{
The endometrial capillaries during the normal menstrual cycle: a morphometric study
}

\author{
M.Peek ${ }^{1}$, B.-M.Landgren ${ }^{2}$ and E.Johannisson ${ }^{3,4}$ \\ 'Department of Obstetrics and Gynaecology, University of Sydney, \\ Sydney 2006, New South Wales, Australia, ${ }^{2}$ Department of \\ Obstetrics and Gynaecology, Karolinska Hospital, Stockholm, \\ Sweden and ${ }^{3}$ Clinic of Sterility and Gynaecologic Endocrinology, \\ University Hospital, Geneva, Switzerland \\ ${ }^{4}$ To whom correspondence should be addressed
}

The areas of the capillary lumen, the entire capillary, the endothelial cells and the adventitia, as well as the thickness of the endothelial cell layer and the adventitia were studied using morphometric methods in endometrial samples from $\mathbf{3 4}$ fertile women who had a hormonal profile compatible with normal ovarian function. The biopsies were grouped around the luteinizing hormone surge. The results were calculated as mean values of 72-h periods and related to the mean levels of oestradiol and progesterone circulating in plasma $72 \mathrm{~h}$ prior to the biopsy. The results indicated that the sub-epithelial capillary plexus of the human endometrium undergoes dynamic changes during the normal menstrual cycle with a significant dilatation of the vessels during the post-ovulatory phase. A significant correlation was found between the area of the capillary lumen and the mean level of progesterone circulating in the plasma $72 \mathrm{~h}$ prior to the biopsy $(P=\mathbf{0 . 0 3 7})$. We conclude that the ovarian steroids produced during the normal menstrual cycle are likely to influence sub-epithelial vascularization causing dilatation in the post-ovulatory phase. This dilatation of the sub-epithelial capillaries may be related to the development of oedema appearing in the stroma at the time of the expected implantation. The possible functional significance of the capillary dilatation in terms of implantation, however, needs to be further investigated.

Key words: human/endometrium/normal menstrual cycle/vascularization/morphometry

\section{Introduction}

The increasing need for efficient and reliable contraceptive methods and the rapid improvement of technology related to assisted procreation are factors which have renewed interest in studies of the human endometrium, including investigations of endometrial vascularization. The new, low-dose, steroidal contraceptives are often accompanied by irregular bleeding episodes which make the use of these otherwise effective methods of contraception less acceptable to many women. With regard to assisted conception, most in-vitro fertilization (IVF) programmes have reported an implantation rate of apparently healthy embryos rarely exceeding $25 \%$ per cycle of treatment (Ethics Committee of the American Fertility Society, 1990). One of the reasons for this low implantation rate has been claimed to relate to disturbances in the development of the endometrium. Morphological events observed at the light and/or the electron microscope level, the composition of the extracellular matrix and, proteins and hormones produced by the endometrium in the normal post-ovulatory phase are all factors which may be involved in implantation. However, these factors are still poorly understood. So far, a number of studies have been carried out on the biochemical changes occurring in the endometrium during the normal menstrual cycle (for review, see Seppälä, 1991). The vascularization of the endometrial tissue has been less extensively investigated.

The anatomy of the endometrial vessels during the normal menstrual cycle was described in detail in 1963 by Schmidt-Matthiesen. During the last 30 years, only a few studies have focused on the morphological changes in the endometrial vessels and their potential relationship to sex steroid production during the normal menstrual cycle (Sheppard and Bonnar, 1980; Johannisson and Redard, 1984).

The vascularization of the endometrium may play an important role in implantation (Akerlund, 1991) and a direct effect of the sex steroids on the capillary endothelial cells cannot be excluded (Johannisson, 1986). The influence of the circulating sex steroids on the vascularization of uterine tissues seems to vary according to the localization. The vessels of the myometrium and the basal layer of the endometrium do not seem to be significantly influenced by the sex hormones; however, the vessels of the upper functional layer of the human endometrium are likely to be highly sensitive to the steroid hormones and to undergo significant changes during the normal menstrual cycle (Schmidt-Matthiesen, 1963). This sensitivity has been reported to occur in the most distal part of the spiral arteries, the arterioles, the capillaries, the venous lakes and the veins of the functional layer (Schmidt-Matthiesen, 1963). In the early pre-ovulatory phase, the wall of the most distal arteries is thin and the layer of elastic material is poorly developed. During the pre-ovulatory phase, the arteries continue to grow and to extend further into the functional layer.

Using intra-ocular endometrial transplants in Rhesus monkeys, Markee (1940) described a five-fold increase in the length of the spiral arteries during the late pre-ovulatory phase. The endometrial stroma did not exhibit the same rate of growth and the thickness of the endometrium only doubled during the same period of time. This discrepancy between the growth rate of the vessels and of the stroma may explain the coiling of the arteries which takes place in the late pre-ovulatory phase. During this

\footnotetext{
C) Oxford University Press
} 
phase of the menstrual cycle, the most distal part of the spiral arteries become connected to the sub-epithelial capillary plexus via arterioles. However, the spiral arteries have also been reported to develop small branches at irregular intervals in the functional layer (Fanger and Barker, 1961; Ramsey, 1977).

Like the distal spiral arteries, the sub-epithelial capillary plexus is likely to undergo changes during the normal menstrual cycle. Sheppard and Bonnar (1980) described an increase in the diameter of the capillaries in the post-ovulatory phase. It has also been postulated that a close connection exists between the thin capillaries and the venules by arteriovenous shunts and that this connection gives rise to 'venous lakes' (Schlegel, 1945; Dalgaard, 1945; Bartelmez, 1956). Later, Ramsey (1977) claimed that the function of the so-called 'venous lakes' was to regulate the blood volume and the rate of blood flow in the superficial part of the endometrium.

In spite of the number of morphological studies on the vascular structure of the human endometrium, the relationship between the circulating ovarian steroids and the dynamics of the dilatation and contraction of the endometrial capillary plexus is still poorly understood. The aim of the present study was to investigate the changes in the endometrial capillaries of the upper functional layer of the endometrium during the normal menstrual cycle, by using objective morphometric methods, and to relate the findings to the circulating levels of oestradiol and progesterone present prior to taking the biopsy.

\section{Materials and methods}

\section{Subjects}

Thirty-four healthy women of fertile age with a history of regular menstrual cycles of 24-30 days volunteered for the study. None of them had used steroidal contraceptives or an intrauterine device (IUD) during the previous 3 months and none had had an abortion within the last 6 months or a delivery within 1 year before admission to the study. On admission, a complete gynaecological examination was performed (including a Papanicolaou smear) and the women were instructed to use barrier methods for contraception during the study period.

\section{Study plan}

Daily blood samples of $10 \mathrm{ml}$ were drawn from all women between 10:00 a.m. and 12:00 a.m. from the first day of the menstrual cycle to the day of onset of the next menstrual bleeding. The haematological status of the volunteers was checked before, during and after the sampling period. Only one cycle was studied in each women.

An endometrial biopsy was taken on a predetermined day of the cycle. Hence, endometrial biopsies were obtained on cycle days 10 or 11,14 or 15,18 or 19,22 or 23 and 26 or 27 . The biopsy specimens were taken with a Randall curette (Stille-Werner AB, Stockholm, Sweden) without dilatation of the cervix and without anaesthesia.

\section{Morphological methods}

Half of the biopsy material was immediately fixed in Bouin's solution and used for light microscopic examination after embedding in paraffin, sectioning and staining with haematoxylin-eosin. The other half of the biopsy was fixed in $3 \%$ glutaraldehyde in $0.1 \mathrm{~mol} / \mathrm{l}$ sodium cacodylate buffer $(\mathrm{pH}$ 7.3-7.4) containing $2 \%$ calcium chloride. The material for electron microscopy was further processed by post-fixation in $\mathrm{OsO}_{4}(1 \%)$ for $2 \mathrm{~h}$ at $4{ }^{\circ} \mathrm{C}$, dehydration in graded ethanol solutions and embedding in propylenoxide/Epon.

The material prepared for light microscopy was assessed by morphometrical methods described by Johannisson et al. (1982, 1987). In the electron micrographs, a detailed morphometric analysis was carried out on the capillary structure of the upper functional layer of the endometrium using the method described by Oberholzer (1983). The following measurements were made: the area of the capillary lumen, the area of the entire capillary, the area of the endothelial cells, the area of the adventitia, the thickness of the endothelial cell layer and the thickness of the adventitia. A morphometric instrument type Leitz A.S.M. system (Leitz Wetzler GmBH, Wetzlar, FRG) was used.

The statistical analyses of the results from the electron microscope study were carried out using a test for normal distribution followed by an unpaired $t$-test. For the correlation studies between the circulating levels of sex steroids (oestradiol and progesterone) and the lumen area of the capillaries, the Spearman rank correlation test was used.

\section{Hormone assays}

In the daily blood samples, plasma oestradiol was estimated by the method of Aso et al. (1975) and plasma progesterone following chromatographic purification on celite columns as described by Brenner et al. (1973). Luteinizing hormone (LH) was estimated by the in-vitro bioassay method of Van Damme et al. (1974), as adapted to assays conducted in plasma by Romani et al. (1976) and Rajalakshmi et al. (1979).

\section{Definitions}

The days of the onset of menstruation and of the midcycle $\mathrm{LH}$ surge were used as points of reference. The cycle was divided into a pre-ovulatory phase, defined as the period from the first day of the cycle to the day of the LH surge (included), and a post-ovulatory phase, consisting of the period from day $\mathrm{LH}+1$ to the day of onset of the next menstruation (excluded). The results of the morphometric assessments were grouped around the day of the LH peak ( $\mathrm{LH} 0$ ) in $72 \mathrm{~h}$ periods. The characteristics of a normal menstrual cycle with regard to the daily levels of LH, ostradiol and progesterone were as established by Landgren et al. (1980). Luteal function was considered to be adequate and within the range of normal variation when plasma progesterone reached a maximum of $32-92 \mathrm{nmol} / \mathrm{l}$ and was maintained at $\geq 16$ $\mathrm{nmol} / \mathrm{l}$ for a minimum of 5 days.

\section{Results}

Following the criteria of a normal menstrual cycle defined above, the endometrial material representing eight groups of $72 \mathrm{~h}$ periods was related to the LH peak. Material from five patients was investigated in three groups, from four patients in four groups and from three patients in one group. The results of the 
Table I. Changes in the endometrial capillary structure during the normal menstrual cycle in 34 women (mean of $40-50$ capillaries \pm SEM)

\begin{tabular}{lcccccccc}
\hline & $\begin{array}{l}\mathrm{LH}-8 /-6 \\
(n=4)\end{array}$ & $\begin{array}{l}\mathrm{LH}-5 /-3 \\
(n=4)\end{array}$ & $\begin{array}{l}\mathrm{LH}-2 / 0 \\
(n=4)\end{array}$ & $\begin{array}{l}\mathrm{LH}+1 /+3 \\
(n=4)\end{array}$ & $\begin{array}{l}\mathrm{LH}+4 /+6 \\
(n=5)\end{array}$ & $\begin{array}{l}\mathrm{LH}+7 /+9 \\
(n=3)\end{array}$ & $\begin{array}{l}\mathrm{LH}+10 /+12 \\
(n=5)\end{array}$ & $\begin{array}{l}\mathrm{LH}+13 /+15 \\
(n=5)\end{array}$ \\
\hline $\begin{array}{l}\text { Area of } \\
\text { capillary } \\
\text { lumen }\left(\mu \mathrm{m}^{2}\right)\end{array}$ & $51.0 \pm 4.8$ & $42.9 \pm 10.4$ & $43.3 \pm 2.8$ & $61.0 \pm 2.6 *$ & $70.8 \pm 16.1$ & $96.2 \pm 25.1$ & $86.1 \pm 20.6$ & $693 \pm 14.9$ \\
$\begin{array}{c}\text { Area of entire } \\
\text { capillary }\left(\mu \mathrm{m}^{2}\right)\end{array}$ & $1973 \pm 7.5$ & $1731 \pm 29.1$ & $1650 \pm 11.0$ & $185.9 \pm 126$ & $2124 \pm 20.3$ & $228.7 \pm 15.8$ & $235.1 \pm 339$ & $2366 \pm 376$ \\
$\begin{array}{l}\text { Largest diameter } \\
\text { of capillary }\end{array}$ & $12.5 \pm 0.9$ & $11.4 \pm 21$ & $13.1 \pm 0.3$ & $13.4 \pm 0.4$ & $145 \pm 1.6$ & $14.6 \pm 21$ & $15.2 \pm 18$ & $14.9 \pm 1.3$ \\
$\begin{array}{l}\text { lumen }(\mu \mathrm{m}) \\
\text { Area of endothelial } \\
\text { cells }\left(\mu \mathrm{m}^{2}\right)\end{array}$ & $113.6 \pm 5.7$ & $95.8 \pm 26.3$ & $88.5 \pm 113$ & $852 \pm 13.0$ & $101.5 \pm 140$ & $88.6 \pm 12.0$ & $113.3 \pm 315$ & $1227 \pm 31.8$ \\
$\begin{array}{c}\text { Area of } \\
\text { adventitia }\left(\mu \mathrm{m}^{2}\right)\end{array}$ & $327 \pm 7.5$ & $343 \pm 8.9$ & $34.2 \pm 1.9$ & $397 \pm 24$ & $40.1 \pm 41$ & $43.9 \pm 6.6$ & $35.8 \pm 41$ & $44.6 \pm 8.5$ \\
\hline
\end{tabular}

*Significant difference when compared with $\mathrm{LH}-2 / \pm 0(P=0.007)$

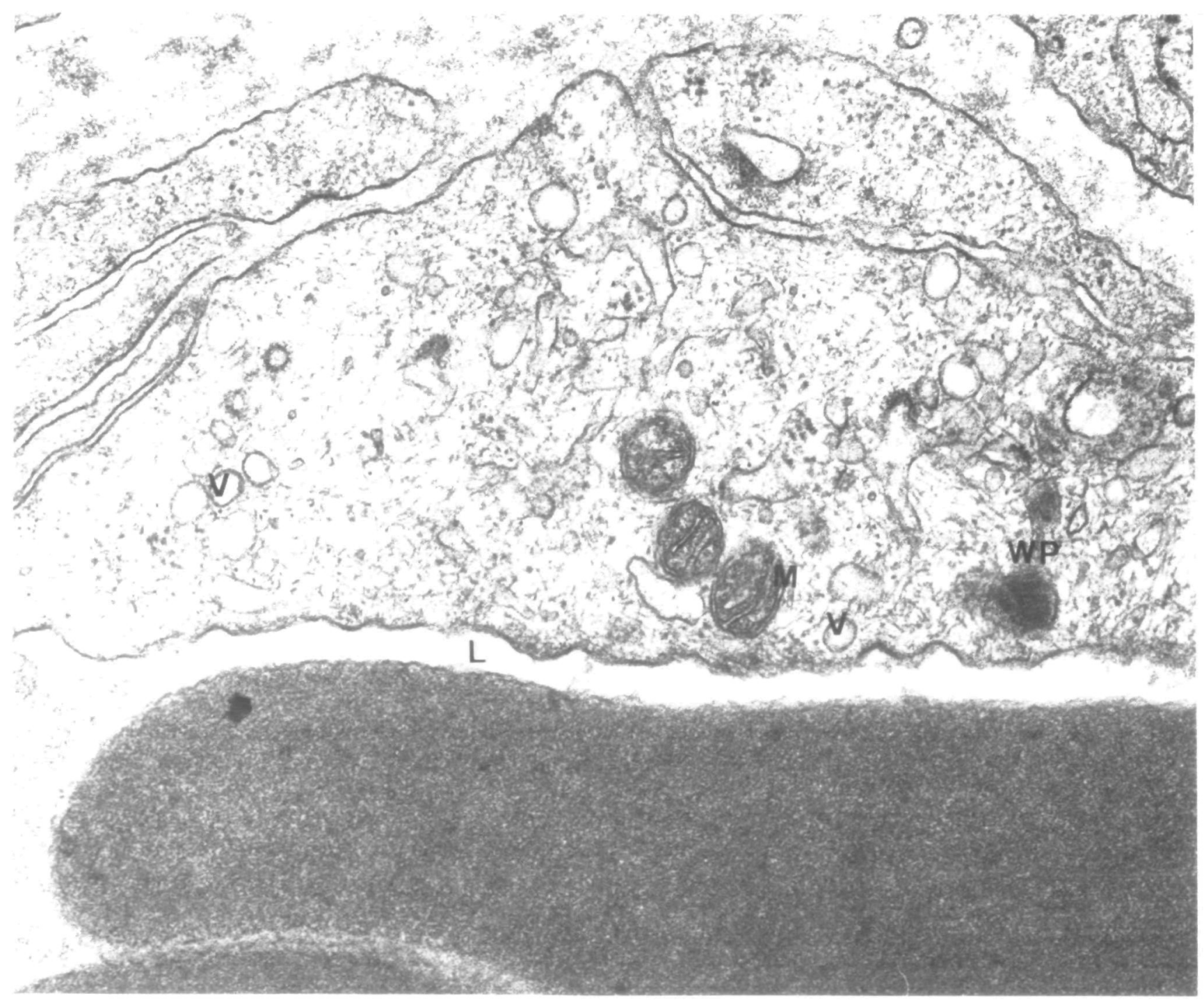

Fig. 1. Part of an endothelial cell of the sub-epithelial capillary plexus in the late proliferative phase (day LH -4). The plasmalemmal vesicles (V) were evenly distributed in the cytoplasm. The mitochondria (M) were well developed. Note the presence of Weibel-Palade bodies (WP) and the smooth surface of the cytoplasmic membrane lining the capillary lumen (L). Magnification $\times 47000$. 


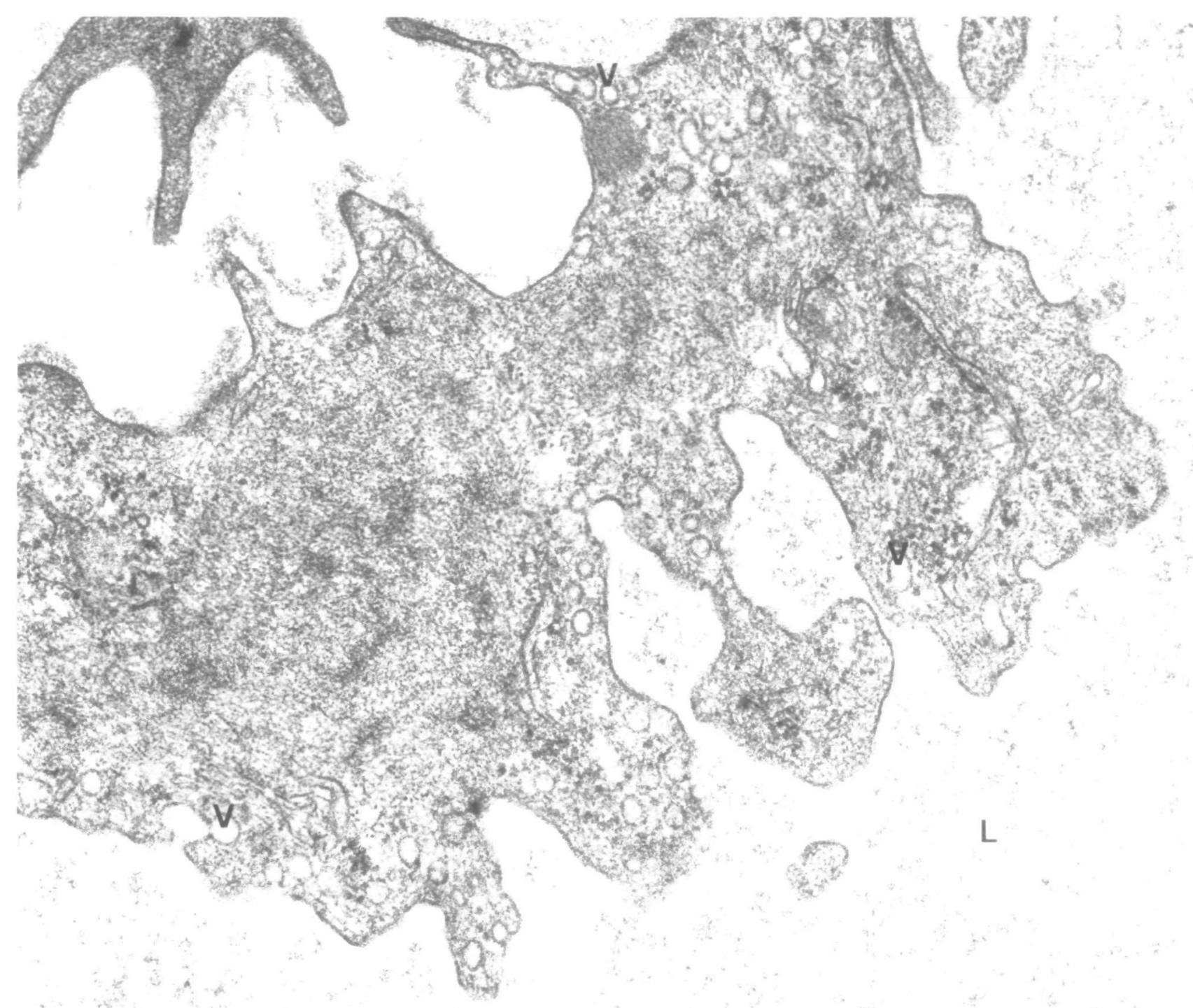

Fig. 2. Part of an endothelial cell of the sub-epithelial capillary plexus of the endometrium obtaned at day LH +6 . The cytoplasmic density was increased compared to the pre-ovulatory phase. The plasmalemmal vesicles (V) were aligned at the periphery of the cytoplasm. Furthermore, numerous cytoplasmic protrusions or 'flaps' were found in the cytoplasm lining the capillary lumen (L). Magnification $\times 47000$.

morphometric assessment of the electron micrographs are shown in Table $\mathbf{I}$.

In respect of the area of the capillary lumen and the area of the entire capillary including the adventitia, a significant increase was found when all biopsies of the pre-ovulatory phase were compared with those of the post-ovulatory phase (area of capillary lumen $P=0.007$, area of the entire capillary including the adventitia $P=0.026$ ). Between groups the differences between the $72 \mathrm{~h}$ periods of the various indices were not clear. However, ovulation seemed to provoke an immediate dilatation of the capillaries.

When the area of the capillary lumen on days LH $-2 / 0$ was compared to that of days $\mathrm{LH}+1 /+3$ a significant increase was found ( $P=0.007$ ). The submicroscopic structure of the endothelial cells during the normal menstrual cycle also revealed changes which could be related to the morphometric findings.
During the pre-ovulatory phase, the capillaries were thin-walled. A large number of plasmalemmal vesicles were found in the cytoplasm, and the cell surface lining the capillary lumen was smooth (Figure 1). The mitochondria were well developed and occasionally Weibel-Palade bodies were observed in the cytoplasm. During the post-ovulatory phase, the cellular matrix of the endothelial cells revealed an increased density. A large number of plasmalemmal vesicles were found, mainly localized at the periphery of the cytoplasm. The cell surface lining the capillary lumen changed from being smooth during the preovulatory phase to displaying a marked irregular appearance with a large number of cytoplasmic protrusions or 'flaps' (Figure 2). Premenstrually, the endothelial cells revealed signs of contraction and degeneration. The cytoplasmic matrix showed an increased electron density. Numerous, so-called 'myelin figures' appeared in the cytoplasm and the endoplasmic reticulum showed dilatation. 


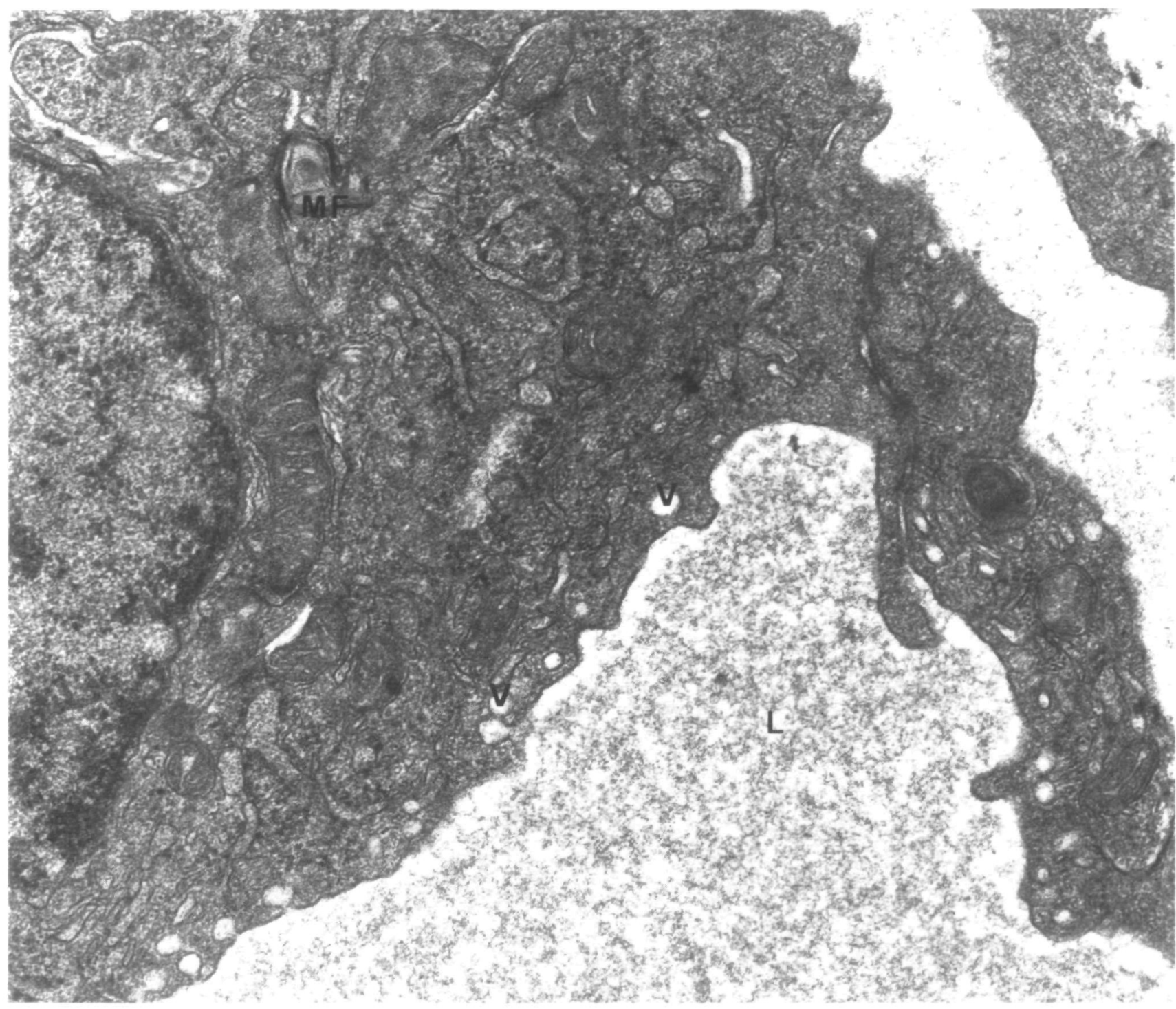

Fig. 3. Part of an endothelial cell lining the sub-epithelial capillary plexus of the endometrium at day LH +14 . The cytoplasm revealed signs of 'contraction'. Several 'myelin figures' (MF) were found. Plasmalemmal vesicles (V) were still present at the periphery of the cytoplasm next to the capillary lumen (L). Magnification $\times 47000$.

The mitochondria became swollen and lost their typical structure of internal cristae. The cell surface lining the capillary lumen displayed fewer protrusions and 'flaps' when compared with the early and mid-secretory phase (Figure 3 ).

Circulating plasma levels of oestradiol and progesterone were then related to the area of the capillary lumen. No significant correlation was found between the mean value of oestradiol circulating in plasma $72 \mathrm{~h}$ prior to the biopsy and the area of the capillary lumen. On the other hand, the mean value of plasma progesterone $72 \mathrm{~h}$ preceding the biopsy showed a significant correlation with the mean area of the capillary lumen (Spearman rank correlation test $P=0.037$ ).

\section{Discussion}

The results of the present study indicate that the sub-epithelial capillary plexus of the human endometrium undergoes dynamic changes during the normal menstrual cycle. During the preovulatory phase, the capillaries are thin-walled and have a narrow lumen. Following ovulation, the size of the capillaries increases mainly due to dilatation of the lumen. The area of the capillary lumen increases slightly up to day $\mathrm{LH}+7 /+9$ which is the time when implantation of the blastocyst is likely to take place (Seppälä, 1991). It is noteworthy that the area of the capillary lumen was significantly correlated with circulating plasma progesterone levels. This observation supports the data from animal studies that the vascular dynamics and the functional properties of endothelial cells are factors which may be important for the nidatory mechanism of implantation (Christoffersson and Nilsson, 1988).

The development of stromal oedema coincides with dilatation of the capillaries. The maximum stromal oedema has been reported to be reached on day $\mathrm{LH}+10 /+11$ (Johannisson et al. . 1987). It is conceivable that the stromal oedema reflects changes 
in the permeability of the endothelial cells. The permeability of endothelial cells is usually described in electron microscope studies as related to the presence of plasmalemmal vesicles, transendothelial channels and/or fenestrated endothelial structures (Majno and Joris, 1978). The various types of pores and openings in continuous and fenestrated endothelial cells are all likely to be involved in the permeability and transport mechanism, and these structures are known to react to a variety of injuries (e.g. inflammation, heat, freezing, thawing, ischaemia, etc.). The effect of steroid hormones on endothelial cells has been described in animal experiments as partially similar to that of injuries induced by mild heat (Majno and Joris, 1978). Oestradiol administered to immature female rats was found to induce escape of plasma and consequent oedema in the myometrium through transient gaps in the endothelium. The predominant pattern of endothelial leakage was capillary and of long duration (Majno and Joris, 1978).

Ethinyloestradiol injected into female rats was reported to increase the susceptibility of the endothelium to injuries induced by a number of test substances (Majno and Joris, 1978). In this respect, it is interesting that Psychoyos (1971) and Abrahamsohn et al. (1983) demonstrated an increase of capillary permeability as the earliest detectable response of the endometrium at the beginning of implantation in rodents. It is likely that such an increased permeability of capillary endothelial cells will permit complexes of serum proteins to cross the blood vessel walls and thereby influence the development of stromal oedema.

The interaction between the production of ovarian steroids, the vascular dynamics of the endometrial capillaries of the functional layer, the permeability of the capillary endothelial cells and the development of oedema in the endometrial stroma is likely to be a highly complex phenomenon which is still incompletely understood. Further studies are required to elucidate this relationship.

\section{Acknowledgements}

This work was supported by a grant from the WHO Special Programme of Research, Development and Research Training in Human Reproduction, Geneva, Switzerland and by a grant from the Swiss National Research Foundation (no. 32-28524.90). The expert technical assistance of Mrs E.Jakobsson-Ström and Miss A.Bigliel of Geneva and Miss Rita Schwendimann of Basle is gratefully acknowledged. We are also indebted to Dr Paul Van Look, WHO, Geneva, who read the manuscript and generously provided most valuable critıcism.

\section{References}

Abrahamsohn,P., Lundkvist,O. and Nilsson,O. (1983) Ultrastructure of the endometrial blood vessels during implantation of the rat blastocyst. Cell Tissue Res., 229, 269-280.

Akerlund,M. (1991) Function of blood vessels relative to implantation. In Seppälä,M. (ed.), Factors of Impontance for Implantation. Baillière's Clinical Obstetrics and Gynaecology. Baillière Tindall, London, pp. 15-23.

Aso,T.. Guerrero, R., Cekan,S. and Diczfalusy,E. (1975) A raprd 5 hours radioimmunoassay of progesterone and oestradiol in human plasma. Clin. Endocrinol., 4, 173-182.

Bartelmez,G.W. (1956) Premenstrual and menstrual ischemia and myth of endometrial arteriovenous anastomoses. Am. J. Anat., 98, 69-95.

Brenner,P.F., Guerrero,R., Cekan,S. and Diczfalusy,E. (1973)
Radioimmunoassay method for sex steroids in human plasma. Steroids, 22, $775-780$.

Christoffersson,R.H. and Nilsson,O. (1988) Placentation in the rat: A SEM study of microvascular casts. In Developments in Ultrastructure of Reproduction. Alan R.Liss, New York, pp. 435-442.

Dalgaard,J.B. (1945) The blood vessels of the human endometrium. Acta Obstet. Gynecol. Scand., 26, 342-378.

Ethics Committee of the American Fertility Society (1990) Ethical considerations of the new reproductive technology. Fertil. Steril., 53, (Suppl. 2), 378-388.

Fanger,H. and Barker,B.E. (1961) Capillaries and arteries in normal endometrium. Obst. Gynecol., 17, 543-550.

Johannisson,E. (1986) Effects of oestradiol and progesterone on the synthesis of DNA and the antihaemophilic Factor VIII antigen in human endometrial endothelial cells in vitro. Hum. Reprod., 1, $207-212$.

Johannisson,E., Parker,R.A., Landgren,B.-M. and Diczfalusy,E. (1982) Morphometric analysıs of the human endometrium in relation to peripheral hormone levels. Fertil. Steril., 38, 564-571.

Johannisson,E. and Redard,M. (1984) Culture of human endothelial cells derived from capillaries of the decidual tissue. Act. Obstet. Gynecol. Scand., 63, 27-36.

Johannısson,E., Landgren,B.-M., Rohr,H.P. and Diczfalusy,E. (1987) Endometrial morphology and peripheral hormone levels in women with regular menstrual cycles. Fertil. Steril., 48, 401-408.

Landgren,B.M., Undén,A.-L. and Diczfalusy,E. (1980) Hormonal profile of the cycle in 68 normally menstruating women. Acta Endocrinol., 94, 89-98.

Majno,G. and Joris,I. (1978) Endothelium 1977: A review. Adv. Exp. Med. Biol., 104, 169-225.

Markee,J.E. (1940) Menstruation in intraocular transplants in the Rhesus monkey. Contribution to Embryology. Camegie Institution of Washington Publication, No. 518,28 (no. 177), pp. 219-308.

Oberholzer,M. (1983) Morphometrie in der klinischen Pathologie. Allgemeine Grundlagen. Springer Verlag, Berlin.

Psychoyos,A. (1971) Methods for studying changes in capillary permeability in the rat endometrium. In Daniel,J.C. (ed.), Methods in Mammalian Embryology. W.H.Freeman, San Francisco, pp. 334-338.

Rajalakshmi,R., Robertson,D.M., Choi,S.K. and Diczfalusy,E. (1979) Biologically active luteinizing hormone (LH) in plasma. III. Validation of the in vitro bioassay when applied to male plasma. Acta Endocrinol., 90, 585-590.

Ramsey,E.M. (1977) Vascular anatomy. In Wynn, R.M. (ed), Biology of the Uterus, Plenum Press, New York, pp. 59-76.

Romani,P., Robertson,D.M. and Diczfalusy,E. (1976) Biologically active luteinizing hormone (LH) in plasma. Acta Endocrinol., 83, $454-460$.

Schlegel,J.U. (1945) Arteriovenous anastomoses in endometrium in man. Acta Anat., 1, 284-325.

Schmidt-Matthiesen,H. (1963) Vaskularisierung. In Schmidt-Matthiesen, H. (ed.), Das Normale Menschliche Endometrium. Thieme, Stuttgart, pp. 225-244.

Seppälā,M. (1991) (ed.) Factors of Importance for Implantation. Bailliere's Clinical Obstetrics and Gynaecology, Vol. 5, No. 1. Baillière Tindall, London.

Sheppard,B.I. and Bonnar,J. (1980) The development of vessels of the endometrium during the menstrual cycle. In Diczfalusy,E., Fraser,I.S. and Webb,F.T.G. (eds), Endometrial Bleeding and Steroidal Contraception. Pitman Press, Bath, UK, pp. 65-77.

Van Damme,M.P., Robertsson,D.M. and Diczfalusy,E. (1974) An umproved in vitro bioassay method for measuring luteinizing hormone (LH) activity using mouse Leydig cell preparations. Acta Endocrinol., $77,655-662$

Received on January 13, 1992; accepted on May 8, 1992 